\title{
Perspectives in Business Anthropology: Cultural Production, Creativity and Constraints
}

\author{
Brian Moeran \\ Copenhagen Business School
}

This paper draws on extensive fieldwork in a wide range of creative industries to argue that creativity itself is under-theorized, and should be considered as both enabled and inhibited by numerous constraints guiding the choices made by creative personnel during the course of their work. Six sets of constraints are outlined in the context of different forms of cultural production: material, temporal, spatial, social, representational and economic. It is argued that the performance of creative work is similar in part to Turner's concept of "communitas," when an aura of individual creativity is passed to other participants. This kind of liminal space is also found in creative industry ritual events, which enable participants to communicate on an equal footing and gain knowledge and connections that they can then use at work in their normal everyday lives. These in turn may have a long-term effect on cultural production, creativity and constraints.

\section{INTRODUCTION}

In recent years it has become fashionable for politicians, corporate executives, civil servants and academics to talk about "creativity," "creative hubs," "creative cities," "creative classes," and so on. By so doing they assign (high) cultural value to commercial activities (Negus and Pickering 2004, p.46-9) that are then connected to national interests. Prior to the spring 2010 election, for example, the website of the Department of Culture, Media and Sport in the United Kingdom attributed the importance of creative industries to the fact that they accounted for a significant percentage of the country's GDP, showed greater growth than the economy as a whole, and employed a significant and increasing number of people (1.95 million at the last count) (DCMS, 2009).

In spite, or because, of their interest in the economic implications of creativity, those concerned in the promotion of "creative industries" rarely go beyond rudimentary, even banal, definitions (cf. Florida, 2002, p.5) of what exactly they mean by "creative" or "creativity" or, indeed, of related words used in the context of creativity: "innovation," "individuality," "spontaneity," "originality," "talent," and so on. Instead they treat creativity as though it exists in a well-cushioned vacuum. All that is required to nourish it are the right kinds of people gathered in the right kinds of spaces doing the right kinds of creative activity (which include art, computer 
games, design, fashion, film, media, music and publishing, among others). In this sense, most people in the worlds of business, education and political administration appear to believe in creativity as a form of "immaculate conception" (cf. Hauser, 1982, p.18).

Of course, it does not help that creativity "is one of the most used and abused of terms - at one moment invoked to praise a specific technical skill, at another uttered in the most vague and casual manner" (Negus and Pickering 2004, p.vi). Moreover, as used in the Western world, "it carries too much Romantic baggage - the mystery of inspiration, the claims of genius" (Sennett 2008, p.290), although elsewhere, as in India and Japan for example, creativity tends to be more "quietist" (Gell, 1998, p.30). Such words tend to rest upon mythic ideas, which themselves often embrace contradictory logics. For example, "inspiration is sometimes described as the secret origin of an idea for which there appears to be no external cause, sometimes as the effect of a purely external and coincidental happening, or of an experience which is of no consequence in itself but to which the artist relates the genesis of his work in a causal, though hidden, way" (Hauser 1982, p.19).

There are two problems with which the social sciences have to deal when discussing creative work processes. One is that the relation between inner impulse and actual creative practice is often as obscure to those employed as "creatives" in the cultural or creative industries as it is to politicians, bureaucrats, corporate managers, academics and other educationalists. This suggests a need to examine creative processes in situ: in other words, to make use of the anthropological concept of participant observation to see and experience how creative (and other) people actually go about their work, as well as how they define "creativity". By building up a series of case studies in different creative industries, we might be able to reach some tentative generalizations about the notion of creativity itself (as well as about how it varies in different industries and between national cultures). This is the aim of this article, which makes use of data gathered over several decades during both long- and short-term periods of fieldwork in pottery communities, department stores, an advertising agency, incense manufacturers, and book and magazine publishing houses - primarily, but not exclusively, in Japan. The fact that, like some other anthropologists who have developed other skilled accomplishments as part of their research, I have often myself made and exhibited pots, written advertising copy, tried my hand at making incense and perfume, and written (too many?) books, which has also, I believe, provided me with a visceral grasp of "creativity" that goes beyond mere intellectual understanding.

The other problem derives from the fact that creativity is in part inexplicable. Here creative people are right to assert that it cannot be totally derived from observable social phenomena. The question, though, is the extent to which we understand creative processes as based upon internally generated drive, talent, inclination and so on, on the one hand, or on the other, as conditioned by external relationships. Creativity may be a basic element of life, a universal talent, fun, competitive, surprising and exhibit certain personality traits (Howkins, 2001, p.1012), but that does not explain anything much in sociological terms. And yet, sociologists are not that adept at explaining the surprising interpretations that push the boundaries of existing conventions in different forms of cultural production (Negus and Pickering, 2004, p.151).

So what does explain creativity? Creative products in themselves are characterized by what Howard Becker (2006, p.24) calls a "fundamental indeterminacy". Films, fashion shows, music, and so on vary enormously, even though they may be realized by the same personnel in, to all intents and purposes, the same environments using the same materials. Yet they are all marked by a series of choices: the choice of how to shoot a particular scene, of how to cut and sew a particular material, of how to phrase a musical idea. The "combination of routine and unusual 
choices among available possibilities" gives every creative product its character (Becker, 2006, p.25-6).

What guides such choices, therefore, should be our main concern. What is the range of possibilities from which those working in the creative industries can draw? The argument presented in what follows is that it is the numerous constraints by which choices are guided that need to be considered. Constraints both inhibit and enable creative processes (cf. Negus and Pickering 2004, p.68). In other words, creativity itself is a meaningless concept unless considered in tandem with the constraints under which it operates: specifically, the different kinds of material/technical, temporal, spatial, social, representational and economic conditions under which all industries - not just the creative i ndustries so called-have to function. In this respect, this essay takes up the dialectical relationship between spontaneity and convention, originality and tradition, individual and group, agency and structure, and free will and determinism that has been the subject of debates in the humanities and social sciences for several centuries. This approach is in itself by no means novel (cf. Becker, 1982, p.40-67). Where it differs from previous work is in its focus on cultural production in general and in its systematization of the kinds of conditions constraining creative choices.

\section{CREATIVITY IN CULTURAL PRODUCTION}

What is meant by "creativity" in cultural production? Firstly, as a concept applied to or within the creative industries, it is comparatively new (although older than the term "creative industries" itself). For example, in advertising, the so-called "creativity crisis" (Frank, 1997, p.22) in American business seems to have started in the 1950s and led to a "Creative Revolution" in advertising in the 1960s. Until then those writing about the American advertising industry rarely, if ever, used the word "creative". "Professionalism," "skills," "expertise," and "experience," yes, but not "creative" (Laird, 1998, p.314-315). Rather, they described the jobs in hand: preparing copy and illustrations, or artwork (Hower, 1939, Chapter XII). Similarly, in the field of Japanese ceramics, the word "creative art" (sakuhin) only came into common use in the 1960s with the boom in consumer demand. More generally, the idea of a "creative," as opposed to a "culture" (Adorno and Horkheimer, 1973) or "cultural" (Hirsch, 1972), industry is even more recent.

If the above two examples are driven by consumption, production processes also seem to have had their influence on use of terminology. The idea of "creativity" in the fashion industry, although not entirely absent before the 1960s, appears to have spread with the adoption of outsourcing by French fashion houses - first within France and later to cheap labor markets in eastern Europe, parts of the Middle East, and most of Asia. Likewise, the current discussion of Danish fashion as a "creative industry" has emerged during the past 15 to 20 years, after Danish fashion companies began to outsource all of their garment manufacturing to China and Southeast Asia. In other words, fashion houses' loss of core competences in the making of garments has led to their emphasis on the creative processes involved in their design as a means of maintaining status and their power over subcontractors.

Secondly, creativity is defined in large part as the ability to go beyond material, social and/or ideological constraints (Wolff, 1981, p.24). Thus, no creative team in an advertising agency starts out with a blank piece of paper, but is given a "creative brief" by the client who directs the strategy to be taken by a particular campaign (Clark, 1988, p.53). So, too, for a perfumer, who is guided by a conceptual road map (in a combination of words and/or images) of the fragrance that a designer and fashion house want him (or her) to create (Burr, 2007, p.5-6; see also Moeran, 
2009a). Although copywriters, art directors, or perfumers may occasionally yearn for freedom from the constraints of the brief, most creative personnel recognize that it is the latter that provides "the stimulus for invention" (Bullmore, 1999, p.56). Indeed, one Japanese copywriter argues that the more constraints and conditions laid down by a client the better, since being told to "make something interesting" merely leads the creative team up numerous, unclear, and ultimately blind alleys (Odagiri, 1992, p.111).

Thirdly, the various activities of conception, execution, rationale, support work, and client reaction are all constrained to one degree or another by the fact that the production of creative products is a joint activity involving a large number of people - 180 in an advertising campaign for an automobile that I once worked on, several hundred for most films - and thus consists of "networks of people cooperating" (Becker, 1982, p.35). All those concerned need to be able to recognize that "there are some rules to the game they are playing" (Becker, 1982, p.5), so that conventions become extremely important to successful completion of a campaign. They promote a "climate of creativity" in which different actors can work together to produce an ad campaign, fashion show, or music CD (Moeran, 2009b). In this respect, we should probably turn the idea of "artistic creativity" (Hospers, 1985) on its head. Instead of pursuing questions pertaining to "criteria of creativity" (Hausman, 1979), we should also ask: how do constraints give rise to the idea of creativity? My suggested answer is that six different sets of conditions influence creative work in different forms of cultural production. These are material/technical, temporal, spatial, social, representational, and economic (cf. Goodale and Koss, 1971).

\section{MATERIAL/TECHNICAL CONDITIONS}

In all creative industries, people rely on established conventions (about how a film should be made, a fashion collection shown, a concert put on) in order to go about their work. They all make use of standard equipment and materials, which affect the way they work and the finished form of that work. It is convention that dictates what materials are used, what abstractions are best suited to convey ideas or experiences, and the form in which materials and abstractions are combined (Becker, 1982, p.29).

The emergence of a set of conventions may depend upon the introduction, or lack, of particular materials and accompanying technologies. In the early days of filmmaking, for example, when the film camera was not what it is today, electric light was not strong enough to substitute for natural light. As a result, production companies based in New York and Chicago began to seek out sunny locations during the winter season. This led to the establishment of motion picture companies in southern California where there was a stable climate, a constant supply of natural light, a wide variety of landscape settings, and low wages. As a result, the number of outdoor shootings increased. This in itself encouraged directors to position their cameras more freely, to split camera "takes" into more frequent and shorter shots, and to introduce long shots as they moved actors and animals deeper into space. From such developments emerged the idea of film as spectacle and the particular genre of the Western (Hutter, 2008, p.67-9) which quickly developed its conventions of chases, battles, gunfights, rugged cowboys and so on, which themselves were transferred to the later genre of police detective films.

Given materials, and the techniques available for their use, tend to condition cultural forms. A potter, for example, uses clay and glaze materials to make and decorate his pots. The nature of the clay - in particular, its plasticity - determines in large part what forms the potter can throw 
on the wheel. In one particular style of folk art pottery (Moeran, 1997), clay containing a high degree of iron oxide prevents the throwing of flat plates (because it collapses beyond a certain vertical angle); it also tends to crack at the base if the potter makes it too broad in proportion to the outer rim of the pot. Glaze materials have to be prepared and mixed in such a way that they adhere to the clay and do not fly away during firing. Moreover, since different glaze recipes tend to melt at different temperatures (brown more quickly than green, for example) because of the different ingredients they contain, a potter has to know which parts of his traditional climbing kiln are hotter or cooler than other parts during firing, so that he can fire different glazes to the same overall temperature without risk of excessive breakage. All this can change if he decides to use a different kind of clay, synthetic rather than natural materials for his glazes, and a gas- as opposed to wood-fired kiln.

An incense blender, or perfumer, also has to know her materials. She needs to be aware of how the unpleasant smell of one material on its own can be transformed into something extremely pleasant if mixed in the right proportion with other olfactory materials. She needs, too, to be able to control the intensity and duration of a fragrance given off by a perfume or incense so that it gives off exactly the "right" smell for exactly the "right" length of time in the "right" context (cf. Moeran, 2009a).

In the advertising industry, copywriters use particular forms of punctuation and font size for headlines, while selecting from among different typefaces for a "look" that they feel is best suited to the product advertised. For their part, art directors have numerous illustrated books of photographs and design through which they leaf in search of ideas about how to pose or dress a model, and borrow from them in designing the storyboards that they present to clients. They also use a grid system for illustration and copy layout. Photographers use different camera lenses, apertures, film, and so on to obtain different effects of light, mass, and perspective. Film directors use freeze frames, soft focus, background music, and other filmic conventions in their preparation of television commercials. In all these examples, individual temperament or habits influences just which forms are adopted under which circumstances, but their finished work tends to adhere to established formal conventions.

As hinted above, the introduction of new technology, together with its availability at affordable prices, can change these conventions, as well as the final form of creative products. With the arrival and common use of computers and digital photography, for example, it is possible to make radical alterations to images. Faces are contorted, bodies twisted, limbs elongated. Stray wisps of hair can be removed from, or a beauty spot inserted on, a model's face with a few clicks of a mouse. Airbrushing is the norm, rather than the exception. Digital technology provides art directors, photographers and cameramen with new ways, and new conventions, to carry out their work (Moeran, 2009b). It also allows them to introduce new materials, such as the use of flat liquid crystal display screens in the work of video artists. The development of industrially manufactured steel frames for guitars, together with amplifying equipment, led to a move away from large musical ensembles and to the formation of small bands, which itself instigated the emergence of the genre of rock music (Hutter, 2008, p.65-7, 69-70).

An artist normally works with paints on a canvas. But, as Michael Hutter (2008, p.64) points out: "Oil paints cause severe problems for painters: They react with untreated canvas, making it necessary to protect the canvas with a coating they tend to discolor over time, leaving a brownish tint; and they take weeks to dry, making it necessary to structure the workflow around the drying periods". This in part explains modern American artists' embrace of acrylic paints which use 
synthetic resins, rather than oil, as a binder and enable colors to be applied directly to the canvas without leaving signs of a brushstroke. They also dry extremely fast and are cheap enough to be bought by the gallon. In this way, as with Impressionists' adoption of a synthetic cobalt blue (rather than continued use of the priceless ultramarine developed from lapis lazuli), a new painting style of aesthetic expression (Abstract Expressionism) came into being (Hutter, 2008, p.62-65).

Another material condition comes from the product itself. In pottery production, for example, particular sizes of pots (large lidded jars or umbrella stands) can only be fired in particular parts of the kiln. Given the effects of temperature on glazes and the nature of the kiln being used, this means that large wares tend to be fired in certain colors (brown, transparent), not others (black, green). Similarly, in advertising, different products give rise to different styles of advertising. Alcohol and fashion items tend to be image driven, for example, while washing powders and other staples rely more on information in making their sales pitch. Besides the functions they perform, products are likely to attract or repel consumers because of a particular combination of audio, visual, tactile, olfactory and/or gustatory properties with which they are imbued. Any one or more of these may be picked out as a way of advertising the product as a whole: for example, At 60 miles an hour the loudest noise in the new Rolls Royce comes from the electric clock (Ogilvy, 1983, p.10). The product, therefore, conditions the direction in which creative expression will go - whether it will tend to simplicity and economy, adopt a quiet and persuasive or light-hearted style, develop an emotional or rational personality, and so on (Burnett, 1971, p.72-3).

\section{TEMPORAL CONDITIONS}

A second set of conditions surrounds the use of time in the creative industries. Time is important in three, rather diverse, ways. Firstly, there is what Richard Caves (2000, p.3) refers to as the "time flies" property. When a creative product has to be ready for a particular event or the market has a backwards effect on its planning and execution. Deadlines have to be established and met. My own fieldwork reveals that, in order for a monthly fashion magazine to be in retail outlets on time, one deadline is set by the distributor, another by the printer, and a third by the art department which puts the magazine's sections together into a single "book". Prior to this, numerous other deadlines are imposed for the shooting of fashion stories, the completion of feature articles, the compilation of health, beauty, fashion world gossip, and other pages, extending back to the very first meeting of the editorial board six weeks prior to the magazine being published. A similar set of deadlines is imposed for the submission, printing, and checking by both agency and client of advertising material that goes into each magazine.

Similar temporal constraints are at work in other creative activities. A potter, for instance, has to know which pots to produce when during the eight week cycle between loading, firing and unloading his kiln. Large pots have to be made first, to enable them to dry in time. These are followed by the smallest pots because they have to be dried and pre-fired in a bisque kiln before being glazed. Thereafter the potter concentrates on middle-sized pots, with those requiring parts - handles for jugs, spouts for tea pots - being made before those that, like flower vases, do not.

Time can also be a conditioning factor depending on the medium or communicative channel used. For example, the fact that a fashion show conventionally lasts for an absolute maximum of 20 minutes affects how many items a designer can show, which in itself influences her choice of garments: formal and informal, office and sportswear, evening dress and casual skirt, bridal 
dress, and so on. Similarly, the convention that a film characteristically lasts longer than 90 minutes but less than two hours affects editing decisions and even story line (like the alternate endings of Cinema Paradiso). In advertising, a 15 second television commercial offers extremely limited opportunity for an advertiser to include very much more than its own name and the name of the product or service it is promoting (Moeran, 1996, Chapter 4), whereas a one minute radio commercial enables a fast-talking narrator to give information about a product and even to repeat catchy sell-lines. The shorter the time available to broadcast advertising, the more likely it will rely on "mood" rather than "information" as its mode of persuasion.

Finally, time is important in the sense that every cultural product is conceived, made, advertised, distributed and received in a historical context of all similar products that have preceded it. Ideally, it should differ - if only marginally - from such previous outputs and, ideally, from comparable outputs simultaneously on the market (Hower, 1939, p.338). Thus, this season's fashion show by - say - Donatella Versace should be different from the show she held this time last year, as well as from competing shows by Jean-Paul Gaultier, Louis Vuitton, and other fashion houses. Similarly, all advertising campaigns should, ideally, differ from previous campaigns, both for the product being advertised and for competing products, in order to mark them off as "significant". Creative activity, then, ideally "takes apart the structure which was formerly created but restores it in a more complex form and gives to its components a new meaning, a new value, and a new structural role in the totality of the work" (Hauser, 1982, p.400).

Here the field clearly affects not just the positions taken by individual creative individuals or organizations, but the mode of communication that s/he adopts. Every fashion designer, every film director, every rock artist "expresses himself in the language of his predecessors, his models, and his teachers" (Hauser, 1982, p.30). In other words, the constraints of time in the broader sense of historical continuity mean that creative expression is not "created" so much as "renewed".

\section{SPATIAL CONDITIONS}

The organization of creative work is often characterized by spatial separation of one kind or another. Fashion designers and the seamstresses putting together their clothes do not work in the same room; nor do musicians and sound recorders, art directors and account managers, and so on. It is generally held that such physical separation enables creative processes.

We have already noted some effects of space on different forms of cultural production. Such effects can be material and technical. For example, the fact that large pots can only be placed at the top of a climbing kiln chamber, if they are to avoid breakage, means that they can only by glazed in some colors, not others. The move by film production companies from indoor to outdoor locations in the early $20^{\text {th }}$ century brought about the introduction of new filming techniques. But space can also bring about symbolic effects. In the studio shoot of an advertising campaign, different personnel are assigned to work in different areas of the studio and its annex, but there is a highly charged common symbolic space in which the two key actors, the art director and photographer, take up their positions and negotiate the work in hand (Moeran, 2009b, p.969-72).

Physical location can be symbolically important in the performance of creative outputs. Acting a part in Hamlet in the Shakespeare Theatre in Stratford-on-Avon, for example, can be more inspiring, as well as more anxiety inducing, than playing the same part in a repertory 
theatre in the north of England. Putting on a fashion show in the palace at Versailles can induce a thrill not experienced in a warehouse by the Seine. Playing a Beethoven piano concerto in the concert hall of the Berlin Philharmoniker can be more uplifting than playing the same piece with a different orchestra in the Royal Festival Hall, London. The atmosphere induced by an audience in a particular location often affects actual performance.

Finally, physical location can itself inspire an appreciation of "creativity" on the part of the consumer. The placing of a work of art, for example, and the distance between it and other works of art hanging on the same wall can signify its relative worth. Similarly, placing it behind glass, or on a plinth, also suggests to the consumer that one work may be more "creative" than another.

\section{SOCIAL CONDITIONS}

Social conditions of creativity may be broadly distinguished into three sub-sets: those stemming from the fact that most forms of cultural production consist of close contact and communication (Fukuda, 1992, p.147) among networks of cooperating personnel, those connected with the fact that much creative work is commissioned, and those that affect the content of the creative outputs themselves. Each of these highlights, to different degrees, the delicate balance between the unpredictability of individual habits and the structured rules imposed by the field.

First, every creative industry has a pool of skilled personnel on whom it can draw to carry out some specialized task. Some are in more demand than others because of the, generally technical, nature of their skills; there tends to be an over-supply of those whose roles are thought to contain some element of "creativity" (Becker, 1982, p.77) and thus more than the market can bear (Towse, 1996, p.99). There are two basic organizational principles - one stable, the other discontinuous - underlying the work of the "motley crew" (Caves, 2000, p.6-7) in cultural production. At one extreme, creative personnel are allocated particular tasks because they work for organizations - copywriters for an advertising agency, for example, or stylist for a fashion magazine publisher - and build networks, reputations and careers through their organizational affiliation. Their work thus tends to follow established practice within the ad agency or magazine publishing house and to be subject to internal politics relating to hierarchy, promotion opportunities, gender, and so on (cf. Becker, 1982, p.81-2).

At the other extreme, those forming a pool of support personnel are contracted for each task separately - a freelance copywriter for a single ad campaign, or a model and makeup artist for a fashion shoot. For the most part, it is established personal connections that enable one hair stylist or actress, rather than another, to get a particular job. Their professional specialization in a single task, however, can lead to an overemphasis on the importance of their own contribution and to their paying little attention to, or even questioning (Moeran, 2009b, p.973-5), other aspects of the creative work in which they are involved. It can also lead to their being "type cast": this photographer is good for soft focus images, that for food; this model for a magazine fashion story, that for a catwalk show (and not vice versa).

Precisely because, first, creative work is guided in large part by personal connections, as well as by reputation established by previous assignments; because, second, the elements that go into a creative product cannot be determined; and because, third, there is great uncertainty surrounding the final result - what Caves (2000, p.4) calls the nobody knows property - creative personnel have to build up relations of trust (Becker, 1982, p.87). In fact, trust can be a deciding factor in cultural production (Odagiri, 1992, p.109-110) and ideally exists at three different levels 
of organizational interaction. In the first place, because creative partnerships - like those of copywriter and art director, or photographer and model - are hemmed in by constraints of one sort or another, those involved have to trust each other to be able to work together effectively. Secondly, they have to trust those humdrum personnel outside the partnership to do what is necessary for them to get on with their job without interference. Thirdly, the organization for which they are working (whether provisionally or on a more permanent basis) has to build up trust with other organizations involved - an advertising agency with its client, production company, studio, model agency, and so on (Fukuda, 1992, p.151-2).

Social constraints in creative work also arise from the fact that it is often commissioned. In the art world, for example, patrons have over time had an enormous influence on the selection of an artist's subject matter, materials used, size of work, and so on (Baxandall, 1972). Collectors of contemporary art still commission work (witness Charles Saatchi's commissioning of Damien Hirst's infamous stuffed shark [Thompson, 2008]); it is their likes and dislikes that determine what will, and what will not, come onto the market. In advertising, too, a client has a major role in the selection of campaign ideas put forward by an agency. It may also make certain demands with regard to selection of model, actress or celebrity used in the campaign and the clothes she wears, and even interfere with details of the print ads to be run (Moeran, 1996, p.158-9), as well as tell a photographer how to do his work (Rosenblum, 1978, p.429). The use of one personality rather than another affects the style of an advertisement, since s/he will bring an already established image to the product being advertised and thus affect its representation (Moeran, 1996, p.156).

It can be seen that social constraints affect cultural products themselves in a number of different ways. On the one hand, by commissioning work, patrons of one sort or another (businessmen, gallery owners, museum curators, and government departments) influence the form it takes; on the other, particular combinations of personnel can lead to particular, and predictable, styles of work. Indeed, the more people work together the more likely they are to develop particular routines. Certain film directors work with a "stable" of actors on whom they draw for each successive work and create a certain "style"; jazz instrumentalists team up to form groups that then develop a certain "sound".

\section{REPRESENTATIONAL CONDITIONS}

Although constraints in representation are primarily "aesthetic," they may also be derived from ethical and legal considerations which may be formal and/or informal. In Japanese advertising, for example, advertisers are legally bound to include a ping-pong sound at the end of a TV commercial to signify to viewers that a medical product has been advertised. In many countries of the world, cigarette advertisements must carry a health warning notice that must extend to up to one third of the size of ad itself. Potters living in urban areas are often legally restricted from using wood-fired kilns for environmental reasons. Incense manufacturers cannot now import agar wood and use it in their products because of a ban on its extraction. Perfumers have difficulty obtaining Mysore sandalwood because of Indian Government restrictions on logging activities. All these legal restrictions oblige those working in the creative industries to find alternative solutions: firing pots in an electric kiln, and using synthetic rather than natural oils in incenses and perfumes.

Informal constraints also abound. In some countries (like Japan) comparative advertising is considered to be in "bad taste," while in others (such as the USA) it is quite acceptable. In the 
fashion world, a recent development has been disapproval, or banning, of "size zero" models from the catwalks because they are unrealistically thin. Proposals are also being put forward in one or two European countries' parliaments that the current practice of air brushing models' blemishes so that they appear to be perfect, be treated in the same way as cigarette advertising: with a warning to that effect. If passed, such proposals will become law and affect the representation of virtually all images in the media.

Aesthetic tastes form the main representational constraint upon cultural production. No work that we think of as "contemporary art," no film that we see as an "action film," no perfume that we buy for its "sexiness" is ever marked by an aesthetic that is not an essential and accepted characteristic of contemporary art, action film, or fashion. Each carries its own set of aesthetic conventions - the car chase in an action film, the naked model with half open mouth in a perfume ad - that make the creative product immediately recognizable. In this way, representational conditions sustain different genres.

Aesthetics are often inextricably tied in with material and technical conventions. A composer selects one key rather than another for a melody, and then one note or phrase rather than another because a particular aesthetic of music allows it and not the other. S/he also writes for one instrument or group of instruments rather than another - because stringed, not brass, instruments are seen to be more "suitable" for a romantic piece of music, for instance - and each of the musicians then makes choices about the phrasing or bowing of the final score (Becker, 2006, p.26). Such constraints allow us to call that score (classical, pop, jazz, rock, and so on) "music" rather than mere "noise".

The borders of each of these genres can be pushed, but only so far. In Japanese advertising, creatives liked to talk of being just a "half pace" - no more - ahead of society. If they were a full step ahead, or a half pace behind, nobody would pay attention to their work. Thus, in order to differentiate his client's product (a contact lens) from that of its competitors, an art director decided to color the lens cut green, rather than blue (the color used in all competing ads); he also chose monochrome, rather than full color, for the print ad (Moeran, 1996, p.158-9).

Just how far borders can be pushed would seem to depend both on the nature of the product, and on the social world of which it is a part. The looser the social constraints, the easier it is to innovate, and vice versa. In Japan, when the $13^{\text {th }}$ generation enamel overglaze artist, Imaizumi Imaemon, received a prestigious prize at a national exhibition, one of the judges summarized for me his committee's choice as follows:

"Look. The Imaizumi family has been making bowls like this for centuries. Imaemon's father made one just like this, with its floral motif, and so did his grandfather. So did his great grandfather, and probably several other ancestors before him. But Imaemon has produced something different. Unlike all those before him, he has painted the flowers pink rather than red, and painted them on a grey, rather than customary blue, background. That's why we gave him the Foreign Minister's Prize. He was stretching tradition to the limit." (Interview with Yoshida Kōzō, June 1981)

\section{ECONOMIC CONDITIONS}

First, the general state of a country's economy almost certainly influences the extent to which a creative industry can or cannot be creative, since the "bottom line" tends to take on overriding importance in a recession. The so-called "creative revolution" that took place in the British and 
American advertising industries (as well as in the fashion industry) during the 1960s was made possible by a strong economy; it was pushed aside by the recession following the oil shocks in the 1970s. Similarly, Japanese advertising flourished in the late 70 s and 80 s, only to fade as the country slipped into a prolonged period of little or no growth. In times of prosperity, advertisers are prepared to give creative ideas a chance; in times of hardship, they focus on sales and are not prepared to take risks on "creativity".

Second, the budget put aside for film, rock concert, fashion show or advertising campaign has a huge effect on its form in terms of what can be done where by whom. The concert series, or "spectacular," This is it, that Michael Jackson was rehearsing up to the time of his death, allowed for a multi-purpose stage with mobile ramp, ejection platforms, and numerous stage effects including enormous robot machines and pyrotechnics, as well as a giant video screen with especially shot film, backing singers, musicians, dancers, and aerialist choreography. In contrast, a normal rock concert or festival allows for little more than the standard equipment (lighting and sound) that enables a series of rock groups to perform their music on stage in front of an audience.

Similarly, in advertising, a large appropriation affects the style and expression adopted in a campaign since it enables use of a mass medium like television (with all its temporal constraints, noted earlier). At the same time, a large budget may well enable selection of a foreign (usually exotic), as opposed to domestic, location for filming; a small budget usually means that advertising creativity must be limited to print advertising and function within a studio frame.

A big budget also enables the contracting of (internationally) famous personnel to participate in films, concerts, advertising campaigns, and so on. This not only gives the finished cultural product a certain cache; it usually influences its reception by the public, and in advertising has a further economic effect in that it contributes to a campaign's reach and recall (McCracken, 1989).

\section{CONCLUSION}

This article has outlined how creativity in cultural production is constrained in a number of set ways relating to the effects of materials and techniques used, time, place, people, aesthetics, legalities, and money. Just how many conventions there are within these categories, and just how strong each of them is, will probably correspond to "the nature of the particular social system in which they are found - conservative or progressive, rigid or flexible, hierarchical or egalitarian" (Hauser, 1982, p.32), and so on.

In the discussion so far, not much has been said about what business ethnography in different forms of cultural production reveals about creativity itself. A few points for discussion, therefore, are in order in this concluding section. First, fieldwork makes clear that creativity - or rather, the recognition of creativity - in a social world depends very much on how people work together. Conventions coordinate activity and knowledge of a professional culture defines a group of practicing professionals (Becker, 1982, p.56). The "climate of approval" mentioned at the beginning of this essay is a crucial element in participants' recognition of such knowledge because it encourages all personnel in a theatre play, product design team, or advertising campaign to recognize and support the different sets of expertise that each brings to the production in question (acting, make-up, costumes, props, sets, lighting, and so on). By erasing structural distinctions (the importance of the director vis-à-vis the stage hand, for example), and by allowing different participants to activate their different sets of expertise, this climate of 
approval is ritualized (Malefyt and Morais, forthcoming) and provides the best possibility for creativity (Moeran, 2009b).

The performance of creative work, then, to some extent replicates the "communitas" characterizing rituals as described by Victor Turner (1969). No single person can claim credit for a creative work, since all have played their part. Yet, on either side of this performance, it is recognized that certain roles - for instance, conductor or designer - are socially imbued with an aura of individual creativity (the "maestro"). This is then passed on to other participants - in an orchestra or fashion show - during performance. At the same time, true to the nature of a field of cultural production (Bourdieu, 1993), such institutions - the Berlin Philharmoniker or the house of Chanel - simultaneously confer an aura on the maestro (Simon Rattle or Karl Lagerfeld).

How is this aura transferred? Primarily by means of events - a concert, fashion show, or art exhibition - at which professionals gather and reaffirm their membership of a music, fashion or art world. In institutional sociologists' parlance, such events "configure (or reconfigure) the field" (Lampere and Meyer, 2008; Moeran and Strandaard Pedersen, 2011). In anthropological writings (Appadurai, 1986; Moeran, 1993, 2010), they are ritualized exchanges that take place in a "tournament of value(s)".

The creative work itself can be more or less important in such ritual events. The crowd gathered in a gallery for an exhibition opening tends to pay more heed to others present at, or absent from, the gathering than to the art works on display, the audience at the first night of a play pays close attention to the performance itself and reserves its socialization to the interval, those attending a fashion show fall somewhere between these two, checking out who is sitting where, but also closely watching the garments being paraded on the catwalk. What can be said, though, is that without the event itself there would be no immediately recognizable art, theatre, fashion or other world of cultural production. Events are the products and producers of creative fields.

Just like the performance of creative work, then, events create a liminal space in time where participants gather in a state of semi-communitas. The hierarchical structure of the field is not broken down as such (Turner, 1964) - those present are very aware of who is who - but it is loosened sufficiently to enable temporary interaction among different levels of participants who make use of introductions, acquaintances and conversations to further their interests during the normal daily dealings of the creative world of which they are a part. Inevitably, these will have a long-term effect on future cultural production where creativity will once again, as always, be subject to the kinds of constraints outlined in this essay.

\section{NOTE}

The writing up of this research was made possible by a grant from the Strategic Research Council of Denmark for the project: "Creative Encounters: The Socio-Economic Organization of Creative Industries,” April 2007-December 2011.

\section{REFERENCES}

Adorno, T. and Horkheimer, M. (1973). Dialectic of Enlightenment. London: Allen Lane.

Appadurai, A. (1986). Introduction. In The Social Life of Things, ed. A. Appadurai. Cambridge: Cambridge University Press, 1-72. 
Baxandall, M. (1972). Painting and Experience in Fifteenth Century Italy. Oxford: Oxford University Press.

Becker, H. (1982). Art Worlds. Berkeley \& Los Angeles: University of California Press.

Becker, H. (2006). The work itself. In Art from Start to Finish: Jazz, Painting, Writing, and Other Improvisations, ed. H.S. Becker, R.R. Faulkner and B. Kirshenblatt-Gimblett. Chicago and London: University of Chicago Press, 21-30.

Bourdieu, P. (1990). The Logic of Practice. Cambridge: Polity.

Bourdieu, P. (1993). The Field of Cultural Production. Cambridge: Polity.

Bullmore, J. (1999). The advertising creative process. In The Advertising Business, ed. J.P. Jones. Thousand Oaks, CA: Sage, 51-60.

Burnett, L. (1971). Leo. Chicago: Leo Burnett Company, Inc.

Burr, C. (2007). The Perfect Scent: A Year Inside the Perfume Industry in Paris and New York. New York: Henry Holt.

Caves, R. (2000). Creative Industries: Contracts between Art and Commerce. Cambridge, MA: Harvard University Press.

Clark, E. (1988). The Want Makers - Lifting the Lid off the Advertising Industry: How They Make You Want to Buy. New York: Viking.

Florida, R. (2002). The Rise of the Creative Class... And How its Transforming Work, Leisure, Community, and Everyday Life, New York: Basic Books.

Frank, T. (1997). The Conquest of Cool: Business Culture, Counterculture, and the Rise of Hip Consumerism. Chicago: University of Chicago Press.

Fukuda T. (1992). Seiyaku wa kōkoku no haha desu (Constraints are the mother of advertising). In Kōkoku no dai-nyūmon: kōkoku hihyō-hen (Great Introduction to Advertising: Advertising Appraisal Edition), ed. Y. Amano. Tōkyō: Madora Shuppan 143-153.

Gell, A. (1998). Art as Agency. Oxford: Oxford University Press.

Hauser, A. (1982). The Sociology of Art. London: Routledge \& Kegan Paul.

Hausman, C. (1979). Criteria of creativity. Philosophy and Phenomenological Research 40, (2), 237-249. 
Hirsch, P. (1972). Processing fads and fashions: an organizational set analysis of cultural industry systems. American Journal of Sociology 77, 639-659.

Hospers, J. (1985). Artistic creativity. Journal of aesthetics and art criticism 43, 3, 243-255.

Hower, R. (1939). The History of an Advertising Agency: N.W. Ayer \& Son at Work. Cambridge, MA: Harvard University Press.

Hutter, M. (2008). Creating artistic from economic value: changing input prices and new art. In Beyond Price: Value in Culture, Economics, and the Arts, ed. M. Hutter and D. Throsby. Cambridge: Cambridge University Press, 60-74.

Laird, P.W. (1998). Advertising Progress: American Business and the Rise of Consumer Marketing. Baltimore: Johns Hopkins University Press.

Lampel, J. and Meyer, A.D. (2008). Field-configuring events as structuring mechanisms: how conferences, ceremonies and trade shows constitute new technologies, industries, and markets. Journal of Management Studies 45, 6, 1025-1035.

Malefyt, T. de Waal and Morais, R.J. (2011). Ritual, brands and the creative process: innovation and collaboration in advertising agencies. Culture and Organization 17: forthcoming.

McCracken, G. (1989). Who is the celebrity endorser? Cultural foundations of the endorsement process. Journal of Consumer Research 16, 310-21.

Moeran, B. (1990). Making an exhibition of oneself. The anthropologist as potter in Japan. In Unwrapping Japan, ed. E. Ben-Ari, B. Moeran and J. Valentine. Manchester: Manchester University Press, 117-139.

Moeran, B. (1993). A tournament of value: strategies of presentation in Japanese advertising. Ethnos 58, 1-2, 73-93.

Moeran, B. (1996). A Japanese Advertising Agency: An Anthropology of Media and Markets. London: Curzon.

Moeran, B. (1997). Folk Art Potters of Japan. London: Curzon.

Moeran, B. 2006a. More than just a fashion magazine. Current Sociology 54, 5, 725-744.

Moeran, B. (2006b). Ethnography at Work. Oxford: Berg.

Moeran, B. (2009a). Making scents of smell: manufacturing and consuming incense in Japan. Human Organization 68, 4, 439-450.

Moeran, B. (2009b). The organization of creativity in Japanese advertising production. Human Relations 62, 7, 963-985. 
Moeran, B. (2010). The book fair as a tournament of values. Journal of the Royal Anthropological Institute 16, 138-154.

Moeran, B and Strandgaard Pedersen, J. (eds.). (2011). Negotiating Values in the Creative Industries: Fairs, Festivals and Competitive Events. Cambridge: Cambridge University Press.

Negus, K. and Pickering, M. (2004). Creativity, Cultural Value and Communication. London: Sage.

Odagiri A. (1992). Business o game ni suru (Making a game of business). In Kōkoku no dainyūmon: kōkoku hihyō-hen (Great Introduction to Advertising: Advertising Appraisal Edition), ed. Y. Amano. Tōkyō: Madora Shuppan, 109-118.

Ogilvy, D. (1983). Ogilvy on Advertising. London: Guild Publishing.

Rosenblum, B. (1978). Style as social process. American Sociological Review 43, 422-438.

Sennett, R. (2008). The Craftsman. London: Allen Lane.

Thompson, D. (2008). The \$12 Million Stuffed Shark: The Curious Economics of Contemporary Art and Auction Houses. London: Aurum.

Towse, R. (1996). Market value and artists" earnings. In The Value of Culture: On the Relationship between Economics and Art, (ed.) A. Klamer. Amsterdam: Amsterdam University Press, 96-107.

Turner, V. (1964). Betwixt and between: the liminal period in rites de passage. In Proceedings of the American Ethnological Society, Symposium on New Approaches to the Study of Religion. Seattle: University of Washington Press, 4-20.

Turner, V. (1969). The Ritual Process: Structure and Anti-Structure. New York: Aldine.

Wolff, J. (1981). The Social Production of Art. London: Macmillan. 